\title{
Analysing the behavior of students and lecturers in using social networks for academic and educational purposes
}

\author{
Phuong Thao $\mathrm{Vu}$ \\ Faculty of Business Management \\ Hanoi University of Industry, Viet Nam \\ Cau Dien Street, North Tu Liem District, Ha Noi, Viet Nam \\ Vuthiphuongthao.dhcn@gmail.com
}

\begin{abstract}
This paper aims to study the behavior of using social networks by students and lecturers for learning and training purposes based on a literature review on this topic in different regions of the world in the past 10 years. The results of the review show that there is a difference in the technological behavior between lecturers and their students; which may reduce the effectiveness of educational activities. Based on the research finding, the author proposes some solutions to encourage teachers to use social networks for their work.
\end{abstract}

Index Terms-social network, social networking behavior, technology acceptance behavior, learning activities.

\section{INTRODUCTION}

$\mathrm{S}$ OCIAL networks, in the recent time, are widely accepted and gradually become one of the most important means of communication among students [16]. Research by the authors in different regions shows that university students now use social networks as a space to interact with friends, lecturers; to exchange learning materials, to sharing knowledge, to consolidate specialized knowledge, to research and cooperate [4]. While students consider social networks as an indispensable channel to exchange and seek for information, teaching staff seem to be slower in accepting and using social networks for the same purpose. Because of this contradiction, the paper focuses on solving the following questions: How do students use social networks for learning purposes? Why do they use social networks for learning? How do teachers use social media in their work? Why is there a difference in technology acceptance behavior by lecturer staff and their students?

\section{Literature Review}

\section{A. Student's behavior of using social networks for learning purposes- How and Why.}

In terms of learning purposes, a relatively large amount of research suggests that Facebook is the most useful platform in helping students in learning activities. Ref. [11] was carried out on a sample of 600 students in Pakistan and found that nearly $90 \%$ of students used Facebook for learning purposes. At Delhi University, $71.25 \%$ of students said they use Facebook for research purposes and to collaborate with classmates. Meanwhile, $60 \%$ of Boston University students use twitter to increase professional awareness and professional knowledge [12]. An investigation in Israel found that Facebook and Twitter accounts set up at some universities were effective in sharing knowledge [4].
Regarding the correlation between facebook and learning motivation, Nkhoma et al. found that Facebook has a positive impact on students' learning motivation, through interactive activities, communication, sharing point of views, interests as well as learning materials. The study also shows that the main benefits of social networks in higher education are reflected in the following aspects: strengthening relationships, promoting learning motivation, exchanging learning materials, developing learning and cooperating ability. This means that activities on social networks have the ability to enhance interaction between students and motivate students to participate in the class, especially students with introverted psychological characteristics, who tend to be afraid of face-to-face discussions in class and feel more confident when communicating online. Social networks also allow students to study and work in groups outside of class time. Ref. [5] and [7] argue that cyberspace encourages students to communicate more than when they sit in class, especially in classrooms arranged in such a traditional way (tables and chairs are arranged in a straight line, students must not face each other). Ref. [6] also has an interesting finding that in the process of interacting with teachers via social networks, students can share more personal information. Thanks to which, the lecturer can understand more about the characteristics of the students, including hometowns, interests, and interests. Student profiles can help instructors personalize lessons or have a more effective way of working and approaching. In terms of psychology, Ref. [19] and Ref. [2] carried out in 2012 and 2016 respectively, all agree that students feel more comfortable when exchanging information about academic issues through discussions with other group members.

Regarding learning effectiveness, ref. [14] affirmed that the cooperation and interaction between classmates and teachers via social networks has a positive influence on the working performance of students at universities. $71.25 \%$ of the respondents strongly agree with the above statement because students through social networks can combine online and offline group work to enhance their learning efficiency. The authors found a correlation between frequency of using facebook for academic activities and test results. Most of the students with the best results use facebook to serve their learning. However, this does not mean that the time using facebook is directly proportional to the learning results, the effectiveness of using social networks also depends on the 
purpose of using facebook and the students' time management skills.

Research models and research results of [6] have identified the independent variables as interaction with friends, engagement with class, interaction with teachers through social networks has a positive effect on the dependent variable of learning efficiency. The interaction with classmate was the most strongly impact factor, while the interaction with teachers was identified as the least one; which can be explained by two reasons: first, lecturers adopt technology later than students; the second is because a part of students are shy and have not actively communicated with their teachers, even on social networks.

In another study, 90\% out of 600 Pakistani students surveyed agreed that Facebook is very useful for their study and research activities, especially in exchanging information with colleagues and friends abroad [11]. Social networks are also a space to encourage learners as well as lecturers to share information about learning materials, research, tests, and ask for feedback in groups. By sharing personal research, the person sharing the document will receive suggestions and feedback, the rest of the members could consider that document as learning materials or reference sources.

An Australian study also concluded that social media helps students develop professional knowledge at a deeper level. [18]. Ref. [7] and Ref. [9] agree that exercises at a high level of training have a certain complexity. The students, therefore, are required to spend more time searching for information sources and communicating with classmates, as well as faculty. They soon realize that social networks are an effective support tool. Furthermore, there is a fact that learning theory in class is not enough for students to understand the problem deeply and it is not possible to immediately apply that theoretical knowledge into practice. After class, students need to talk more with classmates, with lecturers and experts, as well. As a result, they can understand more deeply and broadly and have the opportunity to observe the actual work.

From the above literature review, it can be said that studies on the effectiveness of social networks, especially facebook, have been studied over the past ten years in different geographical areas. Although it is interpreted and approached from different angles, most of the authors agree on the positive influence of social networks on the learning motivation of students and their effective learning in the world.

\section{B. Lecturer's behavior of using social networks for educational purposes- How and Why.}

As discussed in the previous sections, the tendency of students to use social networks for learning purposes is an objective phenomenon, and the effectiveness of using these platforms as a learning channel has also been initially recognized in different regions of the world. However, many researchers agree that there is a certain delay in the behavior of adopting technology and using social networks as a teaching tool and supporting teaching activities of lecturers. Ref. [7] shows a number of obstacles in the process of using social networks in training and educating: teachers have not updated technology, teachers adopt technology later than students, teachers are afraid of copyright issues concerning sharing documents. The authors argue that lecturers belong to the previous generation, their perception of social networks has certain differences compared to students. Studies also show that lecturers, especially those of Generation X, who are now over the age of 40 , behave quite discreetly on Facebook. They do not have the habit of sharing personal information as well as sharing values on social networks, while Gen Y teachers are more open and both groups expressed concerns about copyright and intellectual property. However, the demonstrations of the effectiveness of social networks for learning in a series of recent studies provide great encouragement for them to use this tool for educational purposes. Similarly, Ref. [2] and Ref. [13] also agree that lecturers have not strongly used social networks for training and educational purposes as their students, Canadian, American, South African, Australian, UK lecturers rarely use Facebook as an educational tool.

However, the researchers also suggest that educators should use this tool because their research reveals positive results. Ref. [16] and Ref. [8] suggest that educators and software developers should consider applying social networks platforms in educational activities. The authors believe that using Facebook will enhance communication and cooperation between teachers and learners. Furthermore, teachers can encourage students to participate in the learning process. Ref. [10] shows that if lecturers post academic content on Facebook, students' trust in lecturers will increase. Ref. [17] also commented that when lecturers communicate with students on social networking platforms, the distance between lecturers and students is shortened, which can encourage students to participate more actively.

Application of social networks in teaching is a revolution in training because it transcends the boundaries of the traditional classroom. In addition, using social networks also aligns with the student-centered educational philosophy by creating a more flexible and creative learning environment.

\section{Discussion and Suggestions.}

Students today have a different way of learning than previous generations. The way teaching and learning has recently moved from passive learning to co-production of academic content. The content being taught can be flexibly adapted to the needs of each class and every single learner. Social networks have become an indispensable requirement for connecting and exchanging information among Universities, training instructors, professional communities and professional communities with students. Basing on the overview, analysis and discussion of articles on the topic of using social networks in learning and training activities of university students and lecturers, the author give the following suggestions for lecturers to improve the training effectiveness:

Actively interacting with students via social networks: Interacting with students on social networks will make them feel more motivated in exchanging learning information. Lecturers also get faster and more accurate feedback to adjust teaching activities in time. Students, with their own interests, have very diverse and in-depth conversations regarding the subject matter of the faculty. Therefore, lecturers 
themselves will also have the opportunity to expand their knowledge, further research and develop their expertise.

Building individual brands and sharing values with students on social networking platforms. According to the reviewed studies, the prestige of the lecturer increases when students see the teacher's sharing about academics, experiences, point of view and personal interests as well.

Enhancing online teaching skills: Due to objective requirements, the demand for online learning tends to increase. According to the researchers, this demand has increased sharply in the past two years under the impact of the global epidemic. However, this demand will continue to increase even after the epidemic ends, partly due to the improvement in students' online studying skills, partly due to advances in technological infrastructure, especially virtual reality technology in recent times. Due to differences between face-to-face training and online training, instructors should not completely impose lecturing scenarios, teaching methods and learning materials from direct to online classes; trainers need to have their own design for each type.

\section{Limitations of the Paper.}

The paper has a fairly rich source of references in many regions of the world about the behavior of using social networks for the purposes of learning and teaching among students and lecturers. However, the paper has not gathered the studies in Vietnam on this issue. Recommendations are made on the assumption that the technological behavior of young people is similar, regardless of cultural, economic, psychological and social differences. However, we hope that the topic can be suggestive for further studies on the technological behavior of Vietnamese students for learning purposes. Simultaneously, the topic is also a suggestion for studies on lecturers' skills on social media platforms.

\section{REFFERENCES}

[1] Al-Rahmi, W. and Othman, M., 2013. The impact of social media use on academic performance among university students: A pilot study. Journal of information systems research and innovation, 4(12), pp.1-10.

[2] Cooke, S.Social teaching: Students perspectives on the inclusion of social media in Higher education, 2018
[3] Deng, N; Tavares, J. L. From Moodle to Facebook Exploring students' motivation and experiences in online communities students'perceptions of facebook for academic purposes. Comput. Educ. 2013, 68, 167-176.

[4] Forkosh-Baruch, A., Hershkovitz, A. A case study of Israeli higher education institutes sharing scholary information with the community via social networks. Internet High. Educ. 2012, 15, 58-68

[5] Gray, K., Chang, S., and Kennedy, G. (2010). Use of social web technologies by international and domestic undergraduate students: implications for internationalizing learning and teaching in Australian University, Technology Pedagogy and education, 19, 31-46

[6] Griffith, S., and Liyanage, L. (2008). An introduction to the potential of social networking sites in education. Paper presented at the Proceedings of the second emerging technologies conference.

[7] Kennedy, G., Dalgarno, B., Bennet, S., Gray, K., Waycott, J., Judd, T., et al. (2009). Educating the net generation: A handbook of findings for practice and policy. California, USA: Creative commons.

[8] Khan, T; Kend, M; Robertson, S. Use of social media by University accounting students and its impact on learning outcomes. Acc. Educ. $2016,25,534-567$

[9] Hemmi, A., Bayne, S., \& Land, R. (2009). The appropriation and repurposing of social technologies in higher education journal of assisted learning, 25 (Special issue), 19-30

[10] Hew, F K. Students' and teachers' use of Facebook. Comput. Hum. Behav. 2011.27,662-676

[11] Hussain, I. A stydy to evaluate the social medial trends among University students. Procedia Soc. Behav. Sci, 2012, 64,639-645

[12] Madhusudhan, M. Use of social networking sites by research scholars of the University of Delhi: A study. Int. Inf. Libr. Rev. 2012, 44, 100113

[13] Manca, S; Ranieri, M. Facebook and others. Potentials and obstacles of social media for teaching in higher education. Comput. Educ. 2016, 95, 216-230

[14] Mazer, J.P; Murphy, R E; Simonds, C. J. I will see you on Facebook: The effects of computer-mediated teacher self-disclosure on student motivation, affective learning, and classroom climate. Commun.Educ. 2007, 56, 1-17

[15] Nkhoma, M., Lam, T., Richardson, J., Kam, B., and Lau, K.H. (2016), "Developing case-based learning activities based on the revised bloom's taxonomy". Insite 2016: Informing science and IT education Conference. Informing science Institute, pp85-93.

[16] Peruta, A.; Shields, B.A. Social Media in Higher education: Understanding How Colledges and universities Use Facebook. Available on line (accessed on 30 October 2018)

[17] Sanchez, A.R; Cortijio, V; Javed, U. Students'perception of Facebook for academic purposes. Comput.Educ.2014, 70, 138-149

[18] Tower, M; Latimer, S; Hewitt, J.Social networking as a learning tool Nursing students'perception of efficacy. Nurse Educ. Today 2014, 34, 1012-1017

[19] Wodzicki, K; Schwammlein, E; Moskaliuk, J. “Actually, I want to learn" -Study-related knowledge exchange on social networking sites. Internet High.Educ. 2012, 15, 9-14 